\title{
Medicinal plants of Pakistan: challenges and opportunities
}

Volume 6 Issue 4 - 2017

\section{Opinion}

Since the beginning of human civilization medicinal plants have been used for therapeutic purposes against a variety of diseases. It is one of the oldest forms of human healthcare known to date. Medicinal plants and their derivatives contribute more than half of all clinically administered drugs of modern day. Approximately $40 \%$ of newly approved drugs during the last two decades are of natural origin. They not only possess a significant position in drug discovery for treatment of cancer and other infectious diseases but also play a vital role in the revenue generation for many countries including the ones with low economic conditions. In United states the trade in medicinal plants is continuously emerging with $10 \%$ annual increment and more and more people are attracted towards applications of herbal medicines. Currently, USA, China, France, Japan, UK and Italy are considered to be the largest global markets for medicinal plants. The global market for botanical and plant-derived drugs was therefore expected to increase from $\$ 19.5$ billion in 2008 to $\$ 32.9$ billion in 2013, an annual growth rate of $11.0 \%$. With this growth rate, it is estimated that the annual trade in medicinal plant will reach $\$ 5$ trillion by 2050 .

Fortunately, much of the world's rich medicinal plants habituate in the developing world. Pakistan is enjoying a rich and diverse flora of almost 5700 species of which around 2000 are reported to be medicinally important. However, the current digits for Pakistan are far low than the trade of medicinal plants in other countries like India and China. During 2008-2009 Pakistan imported just spices of $\$ 33.29$ million from India. According to FAO Corporate Document Repository, the actual supply/demand of herbs and medicinal plants is in the range of 20,000 tons per annum. Another research reported, 22 species of medicinal plants worth Rs 14.733 million were traded in 1990 while in 2002, this value rose to more than Rs.122million, an eight-fold increase.

This diversity in Pakistan's native flora reflects its varied climatic zones that ranges from arid and semi-arid to temperate and tropical. Some of the important medicinal plants (Figure 1) of Pakistan includes but not limited to;

i. Ephedra procera: Used to treat bronchial asthma, hay fever and heart stimulant. Once a major supply of E. Procera to the world originated from Baluchistan Pakistan.

ii. Withania coagulans: Fresh fruit is emetic, Dried fruit is sedative, diuretic and stomachic. Moreover, it contains anti-cancerous compounds that have already been identified and also the local people drink its fruits extract for Hepatitis C.

iii. Hedera nepalensis: The leaves and the berries are said to be cathartic, diaphoretic and stimulant. A decoction of the plant is used to treat skin diseases.

iv. Aster thomsonii: The Aster genus has been used for the relief of cough and it possesses diuretic, antitumor, antibacterial, antiviral and anti-ulcer activities.

\author{
Nazif Ullah \\ Department of Biotechnology, Abdul Wali Khan University \\ Mardan, Pakistan
}

Correspondence: Nazif Ullah, Department of Biotechnology, Abdul Wali Khan University Mardan, Pakistan, Tel 009233309718064, Email Ullahnazif@awkum.edu.pk

Received: April 06, 2017| Published: April 13, 2017

v. Acer oblongifolium: Cytotoxic, antibacterial, anti-tumour and antifungal activities are known.

vi. Salvia nubicola: Antioxidant, Cytotoxic, and Anti-cancerous activities are recently identified.

vii. Euphorbia wallichii: Uses for the treatment of edema, skin disease, cutaneous anthrax and exanthema. Cytotoxicity (human cell line), antioxidant and DNA protection activities are also known.

viii. Rhazyastricta; Anti-cancerous and Allelopathic activities are known. Locally diabetic patients drink its leaves water extract.

However, it is also matter of fact that these medicinal plants even in their natural habitat are facing number of challenges. Being weeds, they are in direct influence of environmental and climatic fluctuations. Moreover, lack of uniform cultivation practices, pest infections, illegal collection practices and over exploitation not only adversely effects the plant material for production of effective phytomedicines but also deplete the natural reservoirs of these important plants. It is noteworthy that amongst, 5700 plant species of Pakistan, around 700 are endangered including 64 medicinal plants some of which are even extinct now e.g, Asparagus gharoensis, Ajuga bracteosa, Scaveolaplumererii, Scaveolataccada, Allium gilgiticum, Arabidopsis brevicaulis, Saxifragaduthei, Cousiniamatifeldei, Taraxacumchitralicum, Pediculariscaeruleoalbescens, Nepeta schinidii, Bruguieragymnorrhiza and Sonneratia caseolaris.

Therefore, Pakistan is in dire need to not only regulate the earning industry of medicinal plants but to generate a national narrative of preservation and propagation of medicinal plants. Majority of the medicinal plants are found in less developed and far flung rural areas of the country like Gilgit Baltistan, FATA and other parts of KPK and Baluchistan, therefore, it is very important to involve the local governments, which can play a vital role by making the public engagement in this field. This can be done by training the local people for medicinal plant conservation, production, cultivation and transportation. Nonetheless the government should provide linkage of collectors with market and dealers not only at national level but also at international level. 
There is urgent need of creating more functional societies and association related to medicinal plants that can provide information relating to medicinal plants and extracts just like, International Council for Medicinal and Aromatic Plants (ICMAP), American Council for Medicinally Active Plants (ACMAP), British Herbal Medicine Association (BHMA), American Botanical Council (ABC), European Herb Growers Association (EUROPAM), Association for African Medicinal Plants Standards (AAMPS), Federation of Indian Herbal Industry (FIHI) and Government of India National Medicinal Plants Board (NMPB).

The use of modern day biotechnological intervention through invitro cultures and micropropagation can be another solution where one can start production of medicinally important ingredienst right from lab scale to industrial scale production. This will not only produce opportunities for new research, but will also create opportunities for entrepreneurships.
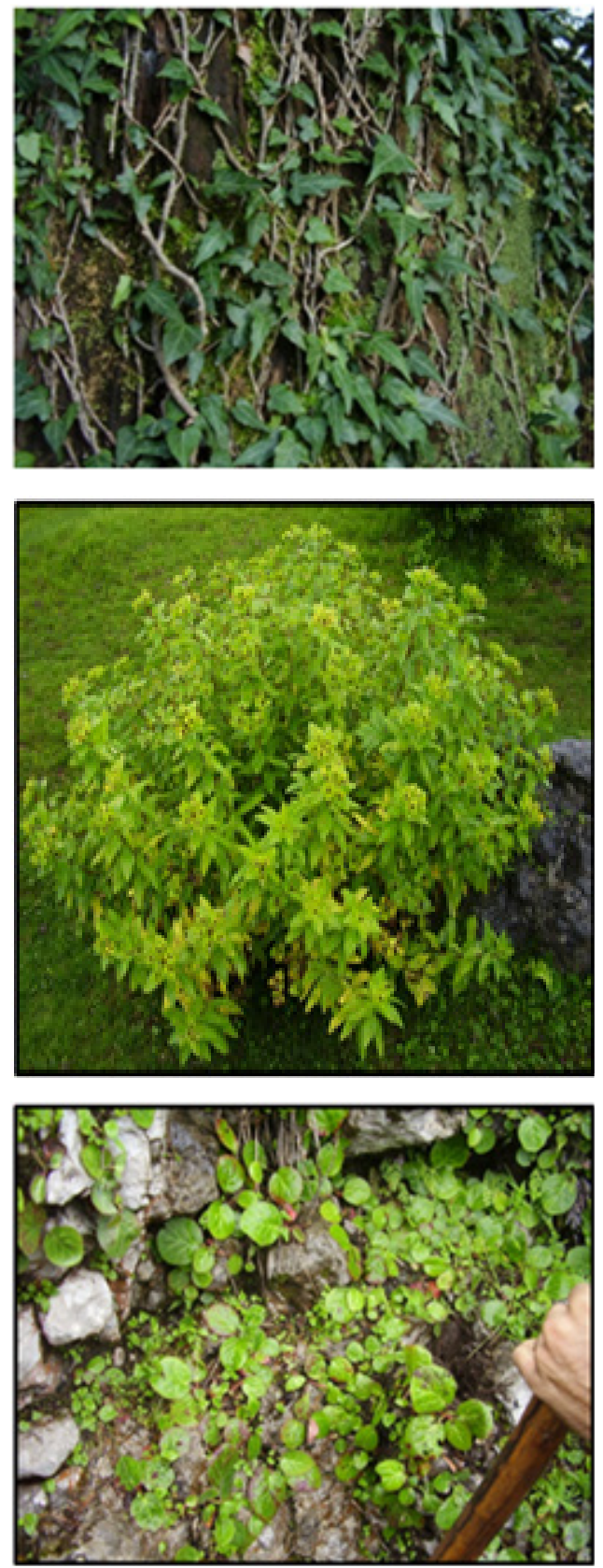
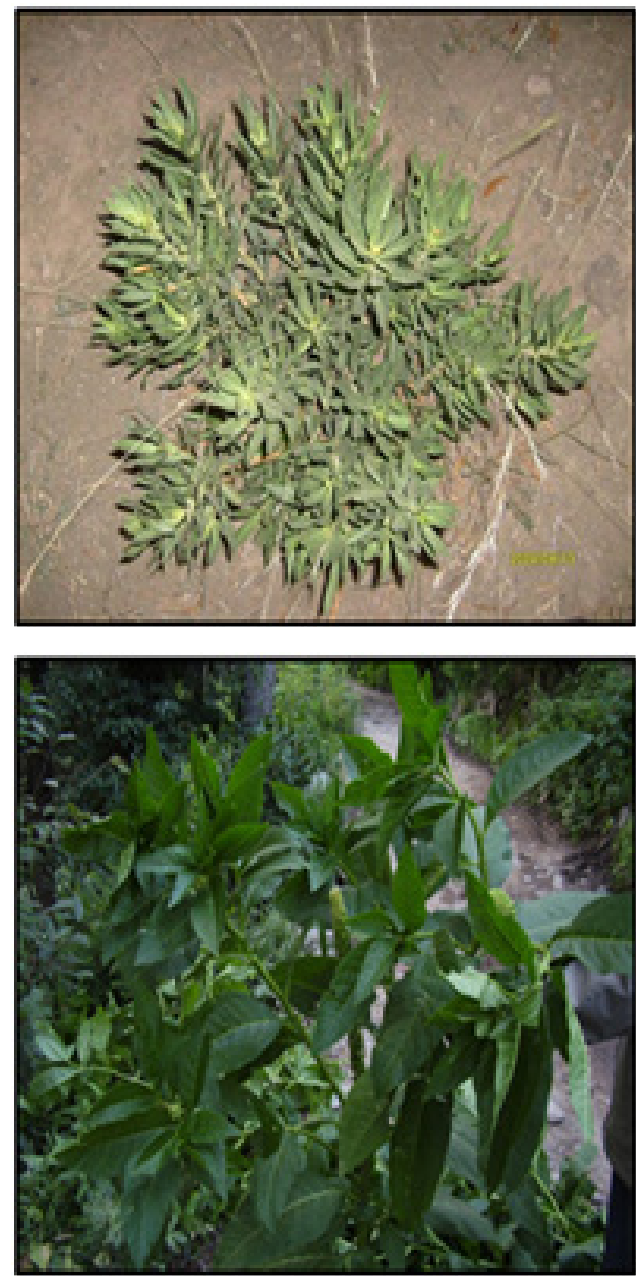

Figure I Some important medicinal plants of Pakistan in their natural habitat i) Hedera nepalensis, ii) Euphorbia wallichii, iii) Bergenia ciliate, iv) Rhazya stricta and v) Phytolacca latbeni

\section{Conclusion}

We can conclude in this article that research and development in medicinal plants is an ignored area in Pakistan and there are plenty of different avenues for research in this field. A vibrant governmental policy and regulation, public awareness and modern biotechnological interventions can result in mass production of these important herbs with sustainable metabolite profiles which intern will give way to establish a medicinal plant industry in Pakistan and hence will support the emerging economy.

\section{Acknowledgments}

The acknowledge Dr. Mubarak Ali, Department of Biotechnology, for reviewing the article.

\section{Conflicts of interest}

Author declares there are no conflicts of interest.

\section{Funding}

None. 